\title{
In reply: Using a Mcintosh blade for retromolar intubation: a comment
}

\author{
Hanife Karakaya Kabukcu, MD • Asli Bostanci, MD • Murat Turhan, MD • \\ Tulin Aydogdu Titiz, MD
}

Received: 20 July 2017/ Accepted: 7 August 2017/Published online: 16 August 2017

(C) Canadian Anesthesiologists' Society 2017

\section{To the Editor,}

We read Drs Veyckemans' and Fayoux's valuable comments $^{1}$ on our report outlining the airway management of a one-month-old infant who presented with an obstructive sublingual cyst. ${ }^{2}$ They recommended cyst aspiration to allow easier direct laryngoscopy. Certainly, in the presence of airway obstruction, intubation after cyst drainage and/or urgent tracheostomy can be options to secure an airway. ${ }^{3}$ However, after respiratory tract obstruction is evaluated with preoperative magnetic resonance imaging (MRI) and no respiratory tract compression is observed, we believe that opting for tracheal intubation without cyst aspiration is a reasonable choice. Nevertheless, we ensured that a surgical team was immediately available to perform urgent cyst aspiration and tracheostomy if needed. In our case, intubation was performed successfully using a curved blade, and urgent cyst aspiration and tracheostomy were not required.

Veyckeman and Fayoux also recommended nasal flexible bronchoscopic (FB) intubation as an alternative technique. Indeed, intubation using a FB permits direct visualization of the glottis to facilitate passage of an endotracheal tube into the trachea and clearly would provide a reliable alternative method in cases of difficult intubation. ${ }^{4}$ This application, however, requires extensive experience and knowledge of complicated pediatric airway

H. K. Kabukcu, MD (ه) · T. A. Titiz, MD

Department of Anesthesiology and Reanimation, Akdeniz

University Medical Faculty, Antalya, Turkey

e-mail: hanifekabukcu@akdeniz.edu.tr

A. Bostanci, MD · M. Turhan, MD

Department of Ear Nose and Throat, Akdeniz University

Medical Faculty, Antalya, Turkey management. ${ }^{5}$ In addition, only very small diameter FBs can be placed through a $3-\mathrm{mm}$ endotracheal tube, ${ }^{3}$ which was not available in our centre.

Veyckemans and Fayoux also referred to muscle relaxant use in cases of difficult intubation, which carries a risk of increased oropharyngeal obstruction due to loss of muscle tone. This risk must be balanced against the potential benefit of preventing laryngospasm. ${ }^{2}$ If intubation could not be performed successfully, we had planned for cyst aspiration and direct intubation.

Lastly, their recommendation for using a straight (i.e., Miller) blade for intubation must be balanced against the difficulty of the advancing the straight blade toward the vallecula during intubation when the cyst may be blocking that route. Indeed, during our first intubation attempt, the tongue could not be moved laterally with a straight blade, and the vocal cords could not be seen. On our second intubation attempt, the laryngoscope was successfully advanced through the right molar gap, and the epiglottis was easily visualized with use of the curved blade. Successful intubation ensued. Accordingly, we believe both straight and curved blades should be kept available prior to intubation and alternative options be considered and made available.

Conflicts of interest None declared.

Editorial responsibility This submission was handled by Dr. Hilary P. Grocott, Editor-in-Chief, Canadian Journal of Anesthesia. 


\section{References}

1. Veyckemans F, Fayoux $P$. Using a Mcintosh blade for retromolar intubation: a comment. Can J Anesth 2017; 64: DOI:10.1007/ s12630-017-0945-6.

2. Kabukcu HK, Bostanci A, Turhan M, Titiz TA. Sublingual heterotopic large cyst in a newborn: anesthetic management. Can J Anesth 2017; 64: 870-1.

3. Black AE, Flynn PE, Smith HL, Thomas ML, Wilkinson KA. Development of a guideline for the management of the unanticipated difficult airway in pediatric practice. Pediatr Anesth 2015; 25: 346-62.

4. Kaufmann J, Laaschat M, Engelhardt T, Hellmich M, Wappler F. Tracheal intubation with the Bonfils fiberscope in the difficult pediatric airway: a comparison with fiberoptic intubation. Pediatr Anesth 2015; 25: 372-8.

5. Karsli $C$. Managing the challenging pediatric airway. Can J Anesth 2015; 62: 1000-16. 